\title{
ORIGINAL ARTICLE \\ Genetic and host-associated differentiation within Thrips tabaci Lindeman (Thysanoptera: Thripidae) and its links to Tomato spotted wilt virus-vector competence
}

\author{
GC Westmore, FS Poke, GR Allen and CR Wilson \\ Of eight thelytokous populations of onion thrips (Thrips tabaci) collected from potato (three populations), onion (four) or \\ Chrysanthemum (one) hosts from various regions of Australia, only those from potato were capable of transmitting Tomato \\ spotted wilt virus (TSWV) in controlled transmission experiments. Genetic differentiation of seven of these eight populations, \\ and nine others not tested for TSWV vector competence, was examined by comparison of the DNA sequences of mitochondrial \\ cytochrome oxidase subunit 1 (COI) gene. All Australian populations of T. tabaci grouped within the European 'L2' clade of \\ Brunner et al. (2004). Within this clade the seven populations from potato, the three from onion, and the four from other hosts \\ (Chrysanthemum, Impatiens, lucerne, blackberry nightshade) clustered as three distinct sub-groupings characterised by source \\ host. Geographical source of thrips populations had no influence on genetic diversity. These results link genetic differentiation \\ of thelytokous T. tabaci to source host and to TSWV vector capacity for the first time.
}

Heredity (2013) 111, 210-215; doi:10.1038/hdy.2013.39; published online 1 May 2013

Keywords: Thrips tabaci; TSWV; vector competence; thelytokous populations

\section{INTRODUCTION}

Onion thrips (Thrips tabaci Lindeman; Thysanoptera: Thripidae) is an important pest species (Lewis, 1973) and was the first recognised vector of the Tospovirus Tomato spotted wilt virus (TSWV; Pittman, 1927), an important pathogen causing significant disease in a wide variety of crop plants (German et al., 1992). Subsequently, T. tabaci has been associated with many TSWV epidemics (Sakimura, 1962; Tsakiridis and Gooding, 1972; Wilson, 1998), but failure of certain populations to transmit TSWV has led to some researchers questioning the importance of the species as a vector of TSWV (Jones, 1959; Paliwal, 1974; Ullman et al., 1997).

The competence of T. tabaci to transmit TSWV has been shown to vary markedly among populations, associated with reproductive strategy, sex, and host preference (Chatzivassiliou et al., 1999, 2002). Transmission studies have shown that thelytokous populations, consisting only of females and reproducing parthenogenetically, fail to transmit (Wijkamp et al., 1995; Chatzivassiliou et al., 2002) or poorly transmit TSWV (Tedeschi et al., 2001). Arrhenotokous populations, which reproduce sexually, are regarded as more efficient TSWV vectors, but this varied with individual's sex and source host plant. Males transmitted TSWV more efficiently than females (Chatzivassiliou et al., 1999, 2002), and populations collected from tobacco were better TSWV vectors than those from leek (Chatzivassiliou et al., 2002). Furthermore, in some studies differing TSWV isolates were transmitted at different efficiency suggesting a possible virus:vector specificity (Chatzivassiliou et al., 1999; Tedeschi et al., 2001).

Variability in $T$. tabaci biology led to speculation about the structure of the T. tabaci taxon. Zawirska, (1976) suggested T. tabaci was comprised of two biotypes; a 'tabaci' type found on tobacco plants which are TSWV vector competent, and a 'communis' type found on onion and other hosts which does not transmit TSWV. Variability in TSWV transmission studies supported the concept that T. tabaci is a heterogeneous taxon (Chatzivassiliou et al., 2002). Brunner et al. (2004) presented genetic evidence for a complex of at least three evolutionary lineages within European T. tabaci populations; two associated with leek and the third with tobacco hosts. These lineages were also found in comparisons of Japanese T. tabaci populations (Toda and Murai, 2007). These findings suggest an ancient origin for the three major phylogenetic lineages. However, these studies did not examine vector competence of the different populations.

Evidence to date suggests all Australian T. tabaci population are thelytokous (Mound and Masumoto, 2005). In spite of this, significant TSWV epidemics clearly associated with $T$. tabaci are reported in Australia (Wilson, 1998, 2001). The aims of this study were to investigate genetic differences between thelytokous $T$. tabaci populations collected from different geographic regions and different plant hosts, and to determine TSWV-transmission capacity within these populations and whether this was associated with any observed genetic differences.

\section{MATERIALS AND METHODS}

Thrips populations

Seventeen Australian thrips populations (16 T. tabaci and one F. occidentalis) were assessed in this study (Table 1, Figure 1). All T. tabaci were thelytokous populations. Colonies were established by collecting adult thrips from a single 
plant of each host type, and transferring an individual adult to a common bean pod where they were reared following a protocol modified from van de Wetering, (1999). All thrips were reared in $7 \mathrm{~cm} \times 9 \mathrm{~cm}$ containers, at $25^{\circ} \mathrm{C} \pm 1{ }^{\circ} \mathrm{C}, 65 \pm 5 \% \mathrm{RH}$, with a photoperiod of L16:D8 in a climate-control chamber, under $450 \mu \mathrm{mol}-\mathrm{m}^{-2} \cdot \mathrm{s}^{-1}$ PAR (photosynthetically active radiation). Thrips were transferred twice-weekly on to fresh common bean pods.

\section{Virus and plants}

Host potato plants (Solanum tuberosum L.; cv. Atlantic) were maintained in tissue culture on potato multiplication medium (4.3 g Murashige-Skoog salts, $30 \mathrm{~g}$ sucrose, $0.5 \mathrm{~g}$ casein hydrolysate, $0.04 \mathrm{~g}$ ascorbic acid made up to 11 with $\mathrm{dH}_{2} 0$, and $8 \mathrm{~g} / \mathrm{l}$ agar type A added before autoclaving) in $7 \mathrm{~cm} \times 9 \mathrm{~cm}$ containers, at $22^{\circ} \mathrm{C}$, near saturation $\mathrm{RH}, \mathrm{L} 16: \mathrm{D} 8$, under cool white fluorescent light. Tissue culture plants were transplanted to soil in $10 \times 10 \mathrm{~cm}$ pots and grown for six weeks in a glasshouse. Other plants used were blackberry nightshade (S. nigrum L.), capeweed (Arctotheca calendula (L.) Levyns), tomato cv. Grosse lisse (S. lycopersicum L.), Datura (Datura stramonium L.) and tobacco (Nicotiana tabacum L.), grown under the same conditions from locally obtained seed. All transmission experiments used TSWV isolate $A n_{W A}-1$, originally obtained from an ornamental Anenome sp. in Western Australia (Dietzgen et al., 2005) and maintained in tomato by serial mechanical inoculation, with periodic vector transmission by natural thrips populations in exposure trials.

\section{Enzyme-linked immunosorbent assay (ELISA)}

TSWV specific antibodies (monoclonal mixture) (Agdia, Elkhart, Indiana USA) were used in double antibody sandwich ELISA. Sap was extracted from the leaf disks $(1 \mathrm{~g} / 10 \mathrm{ml})$ in phosphate buffered saline with Tween (PBS-T) $(1.5 \mathrm{~mm}$ potassium phosphate, $137 \mathrm{~mm}$ sodium chloride, $8 \mathrm{~mm}$ disodium hydrogen phosphate, $2.7 \mathrm{~mm}$ potassium chloride, $10 \mathrm{~mm}$ sodium sulphite, $0.2 \%$ (w/v) bovine serum albumin, $15 \mathrm{ml} / \mathrm{l}$ of Tween 20 and $20 \mathrm{~g} / \mathrm{l}$ of polyvinyl pyrrolidone, $\mathrm{pH}$ 7.4). All samples and known TSWV-positive and negative controls were tested in duplicate. The substrate was $0.5 \mathrm{mg} / \mathrm{ml}$-nitrophenyl phosphate in $97 \mathrm{ml} / 1$ diethanolamine, $\mathrm{pH}$ 9.8. Results were assessed by spectrophotometric measurement of absorbance at $405 \mathrm{~nm}$ using a Labsystems

Table 1 Source plant host, collection site and date for Australian thrips populations used in this study

\begin{tabular}{|c|c|c|c|}
\hline $\begin{array}{l}\text { T. tabaci } \\
\text { population }\end{array}$ & Plant host & Collection site ${ }^{a}$ & $\begin{array}{c}\text { Collection } \\
\text { date }\end{array}$ \\
\hline NSWC & Allium cepa (onion) & $\begin{array}{l}\text { Coleambally, } \\
\text { NSW }\end{array}$ & Oct. 2003 \\
\hline NSWW & A. сера & Whitton, NSW & Nov. 2004 \\
\hline SAM & A. сера & Mypolonga, SA & Dec. 2004 \\
\hline TasBH & A. сера & $\begin{array}{l}\text { Boat Harbour, } \\
\text { TAS }\end{array}$ & Feb. 2005 \\
\hline TASFT & Solanum tuberosum (potato) & Cambridge, TAS & Jan. 2006 \\
\hline TASP & S. tuberosum & Cambridge, TAS & Jan. 2007 \\
\hline TASP1 & S. tuberosum & Cambridge, TAS & Jan. 2007 \\
\hline SAP & S. tuberosum & Penola, SA & Jan. 2007 \\
\hline SAP1 & S. tuberosum & Penola, SA & Jan. 2007 \\
\hline SAP2 & S. tuberosum & Penola, SA & Jan. 2007 \\
\hline SAATL & S. tuberosum & Penola, SA & Jan. 2007 \\
\hline TASCAPE & $\begin{array}{l}\text { Arctotheca calendula } \\
\text { (capeweed) }\end{array}$ & Cambridge, TAS & Jan. 2006 \\
\hline TASCHR & Chrysanthemum sp. & Hobart, TAS & Dec. 2006 \\
\hline TASIMP & Impatiens sp. & Hobart, TAS & Dec. 2006 \\
\hline TASN & $\begin{array}{l}\text { S. nigrum (blackberry } \\
\text { nightshade) }\end{array}$ & Hobart, TAS & Dec. 2006 \\
\hline TASLUC & Medicago sativa (lucerne) & Richmond, TAS & Feb. 2007 \\
\hline TASWFT $^{\mathrm{b}}$ & unknown & Cambridge, TAS & Jan. 2006 \\
\hline
\end{tabular}

anSW, New South Wales; SA, South Australia; TAS, Tasmania.

bFranklinella occidentalis population.
Multiskan RC plate reader with Genesis software (Labsystems, Helsinki, Finland). Samples with absorbance values greater than three times the mean of negative controls were considered positive.

\section{Mechanical inoculation of acquisition host plants}

Three young leaves of each acquisition host plant were mechanically inoculated with TSWV-containing sap from tomato leaves, diluted 1:10 in chilled inoculation buffer $(0.18 \mathrm{M}$ potassium phosphate, $\mathrm{pH} 7.5$, plus $0.15 \%(\mathrm{w} / \mathrm{v})$ cysteine hydrochloride) with a small amount of celite (Celite corporation, Lompoc, CA, USA). Plants were then gently washed to remove sap and celite residues.

\section{Determining vector competence of T. tabaci populations}

The TSWV vector capability of eight T. tabaci populations was tested in a series of glasshouse and laboratory experiments. These included the four populations from onion (SAM, NSWC, NSWW, TASBH), three populations from potato (SAP, TASP, TASFT), and one from Chrysanthemum (TASCHR), the latter population included because it had been collected from a TSWV-infected plant. All thrips populations had been reared on common bean pods for a minimum of five generations before vector competence experiments.

\section{Leaf disk assays with individual thrips}

First-instar larvae less than $12 \mathrm{~h}$ old were placed on freshly picked leaves from a TSWV-infected host plant, with an acquisition access period (AAP) of $24 \mathrm{~h}$. Larval thrips were then individually placed on common bean pods and reared to adults. For each acquisition and transmission host combination, up to 20 adult thrips per population were singly placed on leaf disks ( $20 \mathrm{~mm}$ diameter) cut from young, fully expanded leaves from a virus-free susceptible host in sterile $1.5 \mathrm{ml}$ microcentrifuge tubes with a strip of paper towel to absorb free moisture, with an inoculation access period (IAP) of $72 \mathrm{~h}$. Adults were then removed and leaf disks were incubated for seven days at room temperature.

An equal number of leaf disks from the same host plant were kept thripsfree in microcentrifuge tubes as negative controls. Leaf disks were tested by ELISA for TSWV infection. Six acquisition and transmission host combinations were conducted over ten experiments (Table 2). The first five experiments were conducted in 2006, using the available five populations (TASFT, SAM, NSWC, NSWW, TASBH), with TSWV-infected tomato as the acquisition host. The remaining five experiments were conducted in 2008, using eight

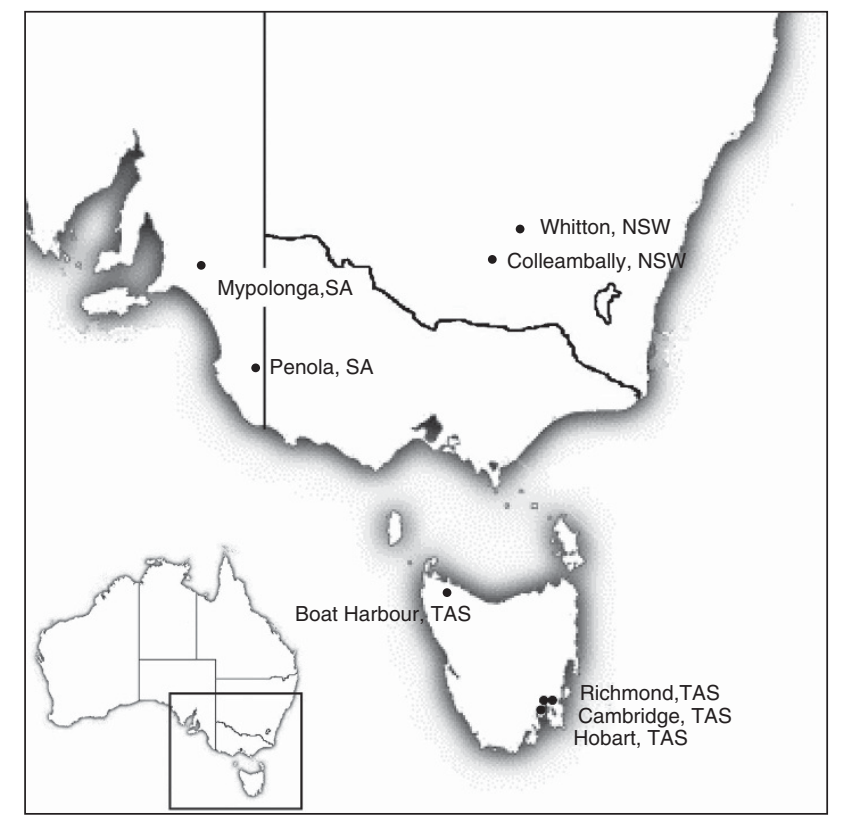

Figure 1 Map showing collection sites of Australian populations of T. tabaci from onion, potato and additional hosts. 
Table 2 TSWV vector competence of eight Australian thelytokous T. tabaci populations originally sourced from potato, onion and chrysanthemum using different acquisition and transmission host combinations and individual thrips per leaf disk

\begin{tabular}{|c|c|c|c|c|c|c|c|c|}
\hline \multirow[t]{2}{*}{ Acquisition/ transmission host } & \multicolumn{8}{|c|}{ Number of TSWV infected leaf disks per total (\%) } \\
\hline & SAP (potato) & $\begin{array}{l}\text { TASFT } \\
\text { (potato) }\end{array}$ & $\begin{array}{c}\text { TASP } \\
\text { (potato) }\end{array}$ & $\begin{array}{c}\text { SAM } \\
\text { (onion) }\end{array}$ & $\begin{array}{l}\text { TASBH } \\
\text { (onion) }\end{array}$ & $\begin{array}{l}\text { NSWC } \\
\text { (onion) }\end{array}$ & $\begin{array}{l}\text { NSWW } \\
\text { (onion) }\end{array}$ & $\begin{array}{c}\text { TASCHR } \\
\text { (chrysanthemum) }\end{array}$ \\
\hline Tomato to tobacco & - & $12 / 12(100)$ & - & - & - & - & - & - \\
\hline Tomato to tobacco & - & $0 / 20(0)$ & - & $0 / 20(0)$ & $0 / 20(0)$ & $0 / 20(0)$ & $0 / 20(0)$ & - \\
\hline Tomato to tobacco & - & $1 / 3(33)$ & - & $0 / 3(0)$ & $0 / 3(0)$ & $0 / 3(0)$ & - & - \\
\hline Tomato to nightshade & - & $2 / 4(50)$ & - & - & - & - & - & - \\
\hline Tomato to tomato & - & $2 / 2(100)$ & - & - & - & - & - & - \\
\hline Datura to Datura & $3 / 10(30)$ & $0 / 10(0)$ & - & $0 / 10(0)$ & $0 / 10(0)$ & - & - & $0 / 10(0)$ \\
\hline Datura to Datura & $3 / 10(30)$ & $2 / 10(20)$ & $2 / 10(20)$ & $0 / 10(0)$ & $0 / 10(0)$ & - & - & $0 / 10(0)$ \\
\hline Datura to tobacco & - & $1 / 10(10)$ & - & $0 / 10(0)$ & $0 / 10(0)$ & - & - & - \\
\hline Datura to potato & $4 / 10(40)$ & - & - & $0 / 10(0)$ & $0 / 10(0)$ & - & - & $0 / 10(0)$ \\
\hline Datura to potato & $0 / 20(0)$ & $0 / 20(0)$ & - & $0 / 20(0)$ & $0 / 20(0)$ & - & - & $0 / 20(0)$ \\
\hline Total transmissions per population & $10 / 50(20)$ & 20/91 (22) & $2 / 10(20)$ & $0 / 83(0)$ & $0 / 83(0)$ & $0 / 23(0)$ & $0 / 20(0)$ & $0 / 50(0)$ \\
\hline
\end{tabular}

Table 3 TSWV transmission capability of five thelytokous $T$. tabaci populations from potato and onion in different acquisition and transmission host combinations using more than 50-100 individuals each experiment

\begin{tabular}{lccccc}
\hline $\begin{array}{l}\text { Acquisition/ transmis- } \\
\text { sion host }\end{array}$ & $\begin{array}{c}\text { TASFT } \\
\text { (potato) }\end{array}$ & $\begin{array}{c}\text { SAM } \\
\text { (onion) }\end{array}$ & $\begin{array}{c}\text { TASBH } \\
\text { (onion) }\end{array}$ & $\begin{array}{c}\text { NSWC } \\
\text { (onion) }\end{array}$ & $\begin{array}{c}\text { NSWW } \\
\text { (onion) }\end{array}$ \\
\hline Tomato to tomato & + & - & - & - & - \\
Tomato to nightshade & + & - & - & - & - \\
Tomato to tobacco & + & - & - & - & - \\
Tomato to capeweed & + & $\mathrm{n} / \mathrm{a}$ & $\mathrm{n} / \mathrm{a}$ & $\mathrm{n} / \mathrm{a}$ & $\mathrm{n} / \mathrm{a}$ \\
Capeweed to & + & $\mathrm{n} / \mathrm{a}$ & $\mathrm{n} / \mathrm{a}$ & $\mathrm{n} / \mathrm{a}$ & $\mathrm{n} / \mathrm{a}$ \\
capeweed & & & & $\mathrm{n} / \mathrm{n} / \mathrm{a}$ & $\mathrm{n} / \mathrm{a}$ \\
Datura to tobacco & + & $\mathrm{n} / \mathrm{a} / \mathrm{a}$ & $\mathrm{n} / \mathrm{a}$ & $\mathrm{n} / \mathrm{a}$ & $\mathrm{n} / \mathrm{a}$ \\
Datura to capeweed & + & $\mathrm{n}$ &
\end{tabular}

Abbreviations: ( $+=$ transmission; - , no transmission; n/a, not tested $)$

populations (the above five and TASP, SAP, TASCHR) and Datura as the acquisition host. Different susceptible transmission hosts were chosen depending on the availability of healthy leaf material at the time of each experiment. For potato, the cultivar Atlantic was chosen because of its known susceptibility to TSWV.

\section{Whole plant assays with multiple thrips}

An additional set of glasshouse experiments were conducted in which a large numbers of adults $(>100)$ from each thrips population was transferred from common bean pods to an infected host plant. At least 100 2nd-instar larvae were then removed from each host plant and reared to adulthood on common bean. All surviving adults from each population were transferred to a healthy susceptible host plant. Successful transmission of TSWV was determined by testing young leaf samples by ELISA four and six weeks after transferral of thrips. Acquisition hosts were tomato, capeweed and Datura and transmission hosts were tomato tobacco, nightshade and capeweed with seven different acquisition and transmission host combinations used (Table 3). These experiments were conducted in 2006, with the five available populations (TASFT, SAM, NSWC, NSWW, TASBH).

\section{Mitochondrial DNA extraction}

DNA was extracted from five T. tabaci individuals collected from each colony in 2008 following the vector competence trials using a modified protocol of Morris and Mound, (2004). Thrips were incubated in a solution of $100 \mu \mathrm{l}$ TNES buffer and $5 \mu$ l Proteinase K $\left(10 \mathrm{mg} \cdot \mathrm{ml}^{-1}\right)$ at either $45^{\circ} \mathrm{C}$ for $5 \mathrm{~h}$, or $37^{\circ} \mathrm{C}$ overnight. The lysis solution was precipitated using $85 \mu \mathrm{l} 5 \mathrm{M} \mathrm{NaCl}$.
The supernatant was removed and DNA precipitated using $400 \mu \mathrm{l}$ of chilled $100 \%$ ethanol. The resulting DNA pellet was washed with $70 \%$ ethanol and dried, and re-suspended in $20 \mu \mathrm{l}$ sterile, $\mathrm{dH}_{2} \mathrm{O}$ before use in PCR.

\section{PCR amplification and DNA sequencing}

A 433 bp fragment of the mitochondrial gene cytochrome oxidase 1 (COI) was amplified using the primers C1-J-1751 and C1-N-2191 (Simon et al., 1994). PCR was performed in $25 \mu \mathrm{l}$ reaction volumes, with $12.5 \mu \mathrm{l}$ HotStarTaq Master Mix (containing HotStarTaq DNA Polymerase, PCR Buffer, and dNTPs, providing a final concentration of $1.5 \mathrm{mM} \mathrm{MgCl}_{2}$ and $0.2 \mathrm{~mm}$ of each dNTP. (Qiagen, Valencia, CA, USA), $0.3 \mu \mathrm{M}$ of each primer and sterile $\mathrm{dH}_{2} \mathrm{O}$, using the following PCR program: denaturation at $95^{\circ} \mathrm{C}$ for $15 \mathrm{~min}, 35$ cycles of $\left(94{ }^{\circ} \mathrm{C}\right.$ $30 \mathrm{~s}, 50{ }^{\circ} \mathrm{C} 30 \mathrm{~s}, 72^{\circ} \mathrm{C} 45 \mathrm{~s}$ ), followed by extension at $72{ }^{\circ} \mathrm{C}$ for $10 \mathrm{~min}$. PCR product was then cleaned using a QIAquick PCR purification kit (Qiagen). Sequences of both forward and reverse strands were obtained with the above primers using the BigDye Terminator v.3.1 kit (Applied Biosystems, Foster City, CA, USA) and the Griffith University DNA Sequencing Facility. Sequences were deposited in Genbank (JQ074095-JQ074109, JQ082479).

\section{DNA analyses}

DNA sequences were edited; consensus sequences generated for each specimen, and the dataset aligned using the AlignX component of Invitrogen Vector NTI Advance 10.3 (Invitrogen Corp, Carlsbad, CA, USA). Phylogenetic trees were constructed using both the neighbour-joining and maximum-likelihood methods implemented in MEGA version 5, with the pair-wise deletion option and 1000 bootstrap replicates (Tamura et al., 2011). Where these two methods showed no difference in branching structure of the tree, the trees derived from the maximum-likelihood method are presented. Branches corresponding to partitions reproduced in less than 50 percent bootstrap replicates were collapsed, and the trees drawn to scale.

Selected European sequences of T. tabaci from Brunner et al. (2004) (Genbank: AY196831, AY196838, AY196840, AY196841, AY196843, AY196844, AY196845, AY196847, AY196848), were combined with the Australian populations of T. tabaci (Genbank: JQ074095-JQ074109) in the phylogenetic tree to place the Australian populations in global context. T. palmi (GenBank: AB277231) served as an intra-generic comparison, because it is considered closely related to T. tabaci (Brunner et al., 2002). F. occidentalis (GenBank: EF555889) and F. occidentalis (GenBank: JQ082479) taken from a protected cropping system in Tasmania served as out-groups.

\section{RESULTS}

Leaf disk assays with individual thrips

Within the ten TSWV transmission experiments, eight resulted in successful virus transmission with some but not all $T$. tabaci 


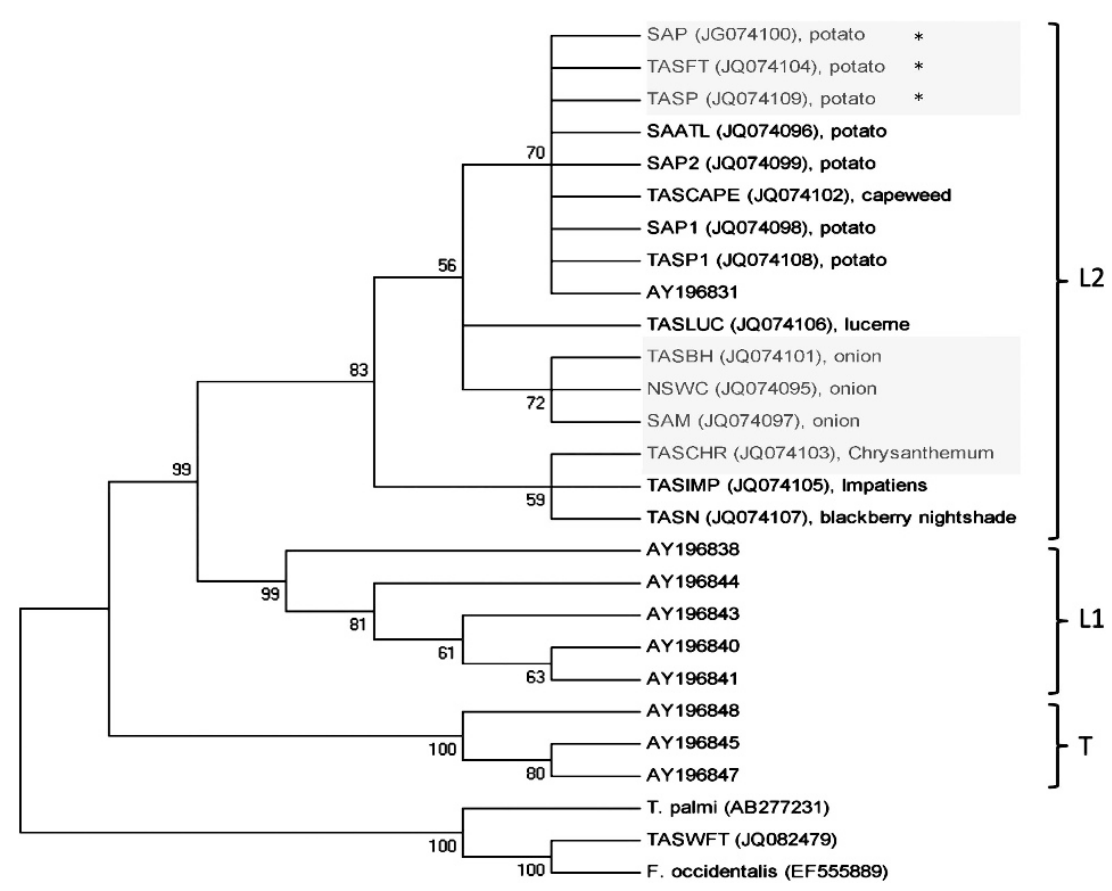

Figure 2 Phylogenetic analysis (The evolutionary history was inferred using the Maximum Likelihood method based on the Tamura-Nei model (Tamura and $\mathrm{Nei}$, 1993). The bootstrap consensus tree inferred from 1000 replicates (Felsenstein, 1985) is taken to represent the evolutionary history of the taxa analysed (Felsenstein, 1985). The percentage of replicate trees in which the associated taxa clustered together in the bootstrap test (1000 replicates) are shown next to the branches (Felsenstein, 1985). Initial tree(s) for the heuristic search were obtained automatically as follows: when the number of common sites was $<100$ or less than one fourth of the total number of sites, the maximum parsimony method was used; otherwise BIONJ method with MCL distance matrix was used. The analysis involved 27 nucleotide sequences. Codon positions included were 1 st $+2 n d+3 r d+$ Noncoding. All positions containing gaps and missing data were eliminated. There were a total of 433 positions in the final dataset. Evolutionary analyses were conducted in MEGA5 (Tamura et al., 2011).) of all T. tabaci populations collected from Australia (Genbank: JQ074095-JQ074109), selected sequences of T. tabaci from Europe (Genbank: AY196831, AY196838, AY196840, AY196841, AY196843, AY196844, AY196845, AY196847, AY196848), T. palmi (GenBank AB277231), F. occidentalis from the United States (GenBank EF555889) and F. occidentalis from Tasmania (Genbank: JQ082479). Clades are marked as per Brunner et al. (2004). Greyed out populations were tested for vector competence. *known TSWV-vector competent populations.

populations (Table 2). The three populations collected from potato (SAP, TASFT, TASP), were able to transmit TSWV, with variable success (0-100\%; Table 2). The four populations collected from onion (TASBH, SAM, NSWC, NSWW), and the population from Chrysanthemum (TASCHR) all failed to transmit TSWV. NSWW was tested once, NSWC tested twice, TASCHR tested four times and TASBH, and SAM tested seven times each.

\section{Whole plant assays with multiple thrips}

In all seven experiments where many (>100) T. tabaci taken from an acquisition host were placed on a single transmission host, successful TSWV transmission occurred using the population from potato (TASFT) regardless of acquisition or transmission host. In contrast no TSWV transmission occurred in any host combination with any of four populations originally sourced from onion in the three experiments in which they were tested (Table 3).

\section{Phylogenetic analysis of T. tabaci populations}

Phylogenetic analysis showed that, the Australian and European populations formed three distinct clades supported by high bootstrap values in accordance with those described by Brunner et al. (2004) and Toda and Murai, (2007) (Figure 2). All Australian populations of T. tabaci from different hosts and from different geographical areas clustered within the 'L2' European clade of Brunner et al. (2004) which contained thelytokous populations from leek from Switzerland, Greece and Bulgaria. The seven T. tabaci populations from potato from different geographical locations in Australia, including all populations that were TSWV vector competent, and one population from capeweed collected from within a potato crop, grouped together in a sub-group supported by a bootstrap score of 70 percent (Figure 2). The three non-TSWV vector populations from onion clustered in a separate sub-group supported by a bootstrap score of 72 percent. Populations from Chrysanthemum (non-vector), Impatiens and blackberry nightshade more loosely clustered in a third subgroup supported by a weaker bootstrap score of 59 percent.

DNA sequence variations between the specimens are shown in Table 4 . Within the sequenced $433 \mathrm{bp}$ fragment of the 15 Australian populations there were six variable sites, averaging one base substitution every 72 base pairs. There were only 2-3 site differences separating populations from onion and potato at positions 87 and 246. All populations from potato had an identical sequence to each other and to AY196831 (from leek, in Switzerland) from Brunner et al. (2004). All variation was in the form of silent, single base-pair substitutions.

\section{DISCUSSION}

Thelytokous populations cannot interact sexually to disperse genetic material. The association of genetically diverse populations with source host, but not geographic location suggests a strong response of preferred host preventing or minimising population mixing (Brunner et al., 2004). The results presented here add to the evidence for presence of distinct sub-populations or biotypes of $T$. tabaci 
Table 4 Variable positions in the $433 \mathrm{bp}$ segment of the COI gene of 15 thelytokous populations of $T$. tabaci from Australia

\begin{tabular}{lcccccc}
\hline Population (source host) & \multicolumn{6}{c}{ Nucleotide positions } \\
\cline { 2 - 7 } & 78 & 87 & 246 & 258 & 309 & 384 \\
\cline { 2 - 7 } & A & G & G & A & G & A \\
TASP (potato) &. &. &. &. &. &. \\
TASCAPE (capeweed) &. & A & A &. &. &. \\
TASCHR (chrysanthemum) & . & A & A &. &. &. \\
TASIMP (Impatiens) &. & A & A &. &. &. \\
TASN (nightshade) &. &. & A &. & A &. \\
TASLUC (lucerne) & G &. & A & C &. & G \\
NSWC (onion) &. &. & A &. &. & G \\
SAM (onion) &. &. & A &. &. & G
\end{tabular}

The reference sequence is TASP (collected from potato in Tasmania). All other populations collected from potato (TASP1, TASFT, SAP, SAP1, SAP2, SAATL) had identical sequences to TASP and are not shown. Dots indicate nucleotides that are identical throughout the compared sequences.

(Zawirska, 1976; Brunner et al., 2004; Toda and Murai, 2007) and provide a credible explanation for the highly variable results in many studies that have sought to determine the vector competence of T. tabaci, including those studies that concluded that this species is unable to transmit TSWV.

T. tabaci TSWV vector competence is associated with source host The TSWV transmission experiments demonstrated TSWV vector competence was associated with source host. All T. tabaci populations from onion failed to transmit TSWV despite repeated attempts in both the individual insect leaf disk assays and in the mass inoculation assays involving transferral of $>100$ individual insects. The population from Chrysanthemum also failed to transmit TSWV in the four leaf disk experiments which used 10 or 20 individual thrips (a total of 50 individuals assayed), but this population was not tested using the mass inoculation assay which is the more robust test of vector competence. In contrast, populations from potato proved efficient TSWV vectors with transmission rates varying from $0-100 \%$ across nine different acquisition-transmission host combinations. Vector efficiency did not appear to be influenced by acquisition or transmission host although the relatively small insect numbers used in each individual test make efficiency comparison difficult.

\section{TSWV vector capacity and host associated differentiation of T. tabaci populations}

Intra-specific variation in vector competence has been demonstrated in many studies for plant and animal viruses. Some studies have simply reported an association (Gray et al., 2002), while others have shown there is genetic control over the ability to transmit a virus, usually through crossings of competent and incompetent populations (Gray et al., 2007). Genetic control of vector competence has been demonstrated for T. tabaci (Cabrera-La Rosa and Kennedy, 2007), other thrips (Halaweh and Poehling, 2009), mosquito (Gray et al., 2007), planthopper (Zeigler and Morales, 1990), whitefly (Brown and Idris, 2005) and aphid (Burrows et al., 2006).

Phylogenetic analysis of Australian T. tabaci populations based on COI sequence comparisons showed clustering corresponded to differences in vector competence and the host from which they were collected. Clustering of the population from capeweed with those from potato was not unexpected as the source plant was within a potato field and the adults collected may have migrated from potato No obvious association of populations with geographic collection site was shown; however, because sympatric populations from potato and onion were not tested for vector competence, the influence of geographical separation rather than host cannot be ruled out. These results add to the concept of $T$. tabaci biotype segregation based on host association (Brunner et al., 2004).

In this study both vector competent and incompetent populations from potato and onion grouped within the 'L2' clade of Brunner et al. (2004) that contains other thelytokous populations sourced from leek. The other 'L2' populations were suggested to be non-vector lineages. Our results show that differences in vector competence between populations occur within at least one of the three major evolutionary lineages, and not just between lineages. Toda and Murai, (2007) found 17 haplotypes of T. tabaci in Japan from across all three lineages proposed by Brunner et al. (2004). Of these, five were thelytokous populations, and only six nucleotide substitutions separated these populations, with 1-4 polymorphic sites amongst the haplotypes. By comparison the five haplotypes found in this study are also separated by only six nucleotide substitutions, albeit at different nucleotide positions, with 2-3 polymorphic sites amongst the haplotypes.

\section{Thelytokous T. tabaci from potato are efficient TSWV vectors} Efficient TSWV transmission in Australian thelytokous populations sourced from potato contrasts with prior studies that demonstrated thelytokous T. tabaci populations fail or are poor TSWV vectors. Zawirska, (1976) and Wijkamp et al. (1995) both showed thelytokous T. tabaci populations from onion did not transmit TSWV. Chatzivassiliou et al. (2002) similarly failed to transmit TSWV with thelytokous populations from leek although they did get efficient or modest TSWV transmission from arrhenotokous populations from tobacco (up to $100 \%$ ) and leek (up to $14 \%$ ) respectively. Tedeschi et al. (2001) showed that thelytokous populations from ornamentals and wild plant species could transmit TSWV albeit inefficiently (0-15\%). Our study suggests that thelytokous T. tabaci can be important vectors in TSWV epidemics and suggests further transmission studies with populations sourced from varying host plants would be worthwhile.

\section{The role of TSWV isolate variation in T. tabaci transmission efficiency}

The efficiency of TSWV transmission by T. tabaci can be influenced by virus isolate. Chatzivassiliou et al. (2002) showed four arrhenotokous populations from leek varied in transmission efficiency of two TSWV isolates with transmission rates for each isolate of 3-24\% or $0-15 \%$ for males and $0-6 \%$ or $0 \%$ for females. Similarly Tedeschi et al. (2001) showed an isolate from Italy was transmitted more efficiently than one from Brazil by Italian thelytokous T. tabaci. Our study used a single TSWV isolate, $A n_{W A} 1$, originally sourced from an Anemone plant in Western Australia. Further investigation of additional isolates would be an interesting extension to the present study. It would be valuable to determine if $T$. tabaci collected from onion are unable to transmit all known TSWV strains, or whether the failure to transmit TSWV in these experiments and those of Zawirska, (1976) and Chatzivassiliou et al. (2002) is because of the TSWV isolates used. Now that complete genome sequences of many TSWV isolates are being reported (Lee et al., 2011), the opportunity exists to study in detail the specific effects of virus genotype on TSWV transmission efficiency. 


\section{T. tabaci as a vector of Iris yellow spot virus (IYSV)}

T. tabaci is the only known vector of a second tospovirus, IYSV, that induces significant disease in various Allium species including onion (Gera et al., 1998). Both thelytokous and arrhenotokous populations found on onion have been shown to transmit IYSV (Inoue et al., 2009; Kritsman et al., 2001). Furthermore, IYSV transmission competent T. tabaci populations have failed to transmit TSWV demonstrating differences in vector association for the two viruses (Nagata et al., 2004). An extension of the present study would be to test IYSV-vector competence of a diverse collection of genetically typed $T$. tabaci populations. This would further our understanding of the ecology and epidemiology of this virus and to gain a better understanding on vector factors associated with tospovirus transmissibility.

\section{DATA ARCHIVING}

Sequence data have been submitted to GenBank: accession numbers JQ074095-JQ074109, JQ082479.

\section{CONFLICT OF INTEREST}

The authors declare no conflict of interest.

\section{ACKNOWLEDGEMENTS}

This work was partially supported by an Australian Research Council (Linkage grant) in partnership with McCain Foods Australia.

Brown JK, Idris AM (2005). Genetic differentiation of the whitefly Bemisia tabaci (Genn.) mitochondria $\mathrm{COI}$ and geographic congruence with the coat protein of the plant virus genus: Begomovirus. Ann Entom Soc Am 98: 827-837.

Brunner PC, Chatzivassiliou EK, Katis NI, Frey JE (2004). Host-associated genetic differentiation in Thrips tabaci (Insecta: Thysanoptera), as determined from mtDNA sequence data. Heredity 93: 364-370.

Brunner PC, Fleming C, Frey JE (2002). A molecular identification key for economically important thrips species (Thysanoptera: Thripidae) using direct sequencing and a PCRRFLP-based approach. Agric Forest Entomol 4: 127-136.

Burrows ME, Caillaud MC, Smith DM, Benson EC, Gildow FE, Gray S (2006). The genetic regulation of polerovirus and luteovirus transmission in the aphid Schizaphisgraminum. Phytopathology 96: 828-837.

Cabrera-La Rosa JC, Kennedy GG (2007). Thrips tabaci and Tomato spotted wilt virus: inheritance of vector competence. Entomol Exp App 124: 161-166.

Chatzivassiliou EK, Nagata T, Katis NI, Peters D (1999). The transmission of tomato spotted wilt tospovirus (TSWV) by Thrips tabaci Lind. (Thysanoptera: Thripidae) populations originating from leek. Plant Pathol 48: 700-706.

Chatzivassiliou EK, Peters D, Katis NI (2002). The efficiency by which Thrips tabaci populations transmit Tomato spotted wilt virus depends on their host preference and reproductive strategy. Phytopathology 92: 603-609.

Dietzgen RG, Twin J, Talty J, Selladurai S, Carroll ML, Coutts BA et al. (2005). Genetic variability of Tomato spotted wilt virus in Australia and validation of real time RT-PCR for its detection in single and bulked leaf samples. Ann Appl Biol 146: 517-530.

Felsenstein J (1985). Confidence limits on phylogenies: An approach using the bootstrap. Evolution 39: 783-791.

Gera A, Cohen J, Salomon R, Raccah B. (1998). Iris Yellow Spot Tospovirus detected in Onion (Allium cepa) in Israel. Plant Dis 82: 127.

German TL, Ullman DE, Moyer JW (1992). Tospoviruses: diagnosis, molecular biology, phylogeny, and vector relationships. Ann Rev Phytopathol 30: 315-348.
Gray SM, Caillaud MC, Burrows M, Smith DM (2007). Transmission of two viruses that cause Barley yellow dwarf is controlled by different loci in the aphid, Schizaphis graminum. J Insect Sci 25: 1-15.

Gray SM, Smith DM, Barbierri L, Burd J (2002). Virus transmission phenotype is correlated with host adaptation among genetically diverse populations of the aphid, Schizaphis graminum. Phytopathology 92: 970-975.

Halaweh N, Poehling H-M (2009). Inheritance of vector competence by the thrips Ceratothripoides claratris (Shumsher) (Thysanoptera: Thripidae. J Appl Entomol 133: 386-393.

Inoue T, Murai T, Natsuaki T (2009). An effective system for detecting Iris yellow spot virus transmission by Thrips tabaci. Plant Pathol 59: 422-428.

Jones JP (1959). Failure of thrips to transmit an isolate of tomato spotted wilt virus. Phytopathology 49: 452-453.

Kritzman A, Lampel M, Raacah B, Gera A (2001). Distribution and transmission of Iris yellow spot virus. Plant Dis 85: 838-847.

Lee JS, Cho WK, Kim MK, Kwak HR, Choi HS, Kim KH (2011). Complete genome sequences of three Tomato spotted wilt virus isolates from tomato and pepper plants in Korea and their phylogenetic relationship to other TSWV isolates. Arch Virol 156: 725-728.

Lewis T (1973). Thrips, Their Biology, Ecology and Economic Importance. Academic Press: London.

Morris DC, Mound LA (2004). Molecular relationships between populations of South African citrus thrips (Scirtothripsaurantii Faure) in South Africa and Queensland, Australia. Austr J Entomol 43: 353-358.

Mound LA, Masumoto M (2005). The genus Thrips (Thysanoptera, Thripidae) in Australia, New Caledonia and New Zealand. Zootaxa 1020: 1-64.

Nagata T, Almeida ACL, Resende R de O, de Avilia AC (2004). The competence of four thrips species to transmit and replicate four tospoviruses. Plant Pathol 53: $136-140$.

Paliwal YC (1974). Some properties and thrips transmission of tomato spotted wilt virus in Canada. Can J Bot 52: 1177-1182.

Pittman HA (1927). Spotted wilt of tomatoes. J Austr Council Sci Ind Res 1: 74-77.

Sakimura K (1962). The present status of thrips-borne viruses. In: Maramorosch K (ed) Biological Transmissions of Disease Agents. Academic Press: New York, pp 33-40.

Simon C, Frati F, Beckenbach A, Crespi B, Liu H, Flook P (1994). Evolution, weighting and phylogenetic utility of mitochondrial gene sequences and a compilation of conserved polymerase chain reaction primers. Ann Entomol Soc Am 87: 651-701.

Tamura K, Nei M (1993). Estimation of the number of nucleotide substitutions in the control region of mitochondrial DNA in humans and chimpanzees. Mol Biol Evol 10: 512-526.

Tamura K, Peterson D, Peterson N, Steker G, Nei M, Kumar S (2011). MEGA5: Molecular evolutionary genetics analysis using maximum likelihood, evolutionary distance, and maximum parsimony methods. Mol Biol Evol 28: 2731-2739.

Tedeschi R, Ciuffo M, Mason G, Roggero P, Tavella L (2001). Transmissibility of four tospoviruses by a thelytokous population of Thrips tabaci from Liguria, Northwestern Italy. Phytoparasitica 29: 37-45.

Toda S, Murai T (2007). Phylogenetic analysis based on mitochondrial COI gene sequences in Thrips tabaci Lindeman (Thysanoptera: Thripidae) in relation to reproductive forms and geographic distribution. Appl Entomol Zoo 42: 309-316.

Tsakiridis JP, Gooding Jr GV (1972). Tomato spotted wilt virus in Greece. Phytopathol Mediterr 11: 42-47.

Ullman DE, Sherwood JL, German TL (1997). Thrips as vectors of plant pathogens. In: Lewis T. (ed) Thrips as Crop Pests. CAB International: New York, pp 539-565.

van de Wetering $F$ (1999). Effects of thrips feeding on tospovirus transmission in Chrysanthemum. Ph.D Thesis Agricultural University of Wageningen The Netherlands.

Wijkamp I, Alarza N, Goldbach R, Peters D (1995). Distinct levels of specificity in thrips transmission of Tospoviruses. Phytopathology 85: 1069-1074.

Wilson CR (1998). Incidence of weed reservoirs and vectors of tomato spotted wilt tospovirus on southern Tasmanian lettuce farms. Plant Pathol 47: 171-176.

Wilson CR (2001). Resistance to infection and translocation of Tomato spotted wilt virus in potatoes. Plant Pathol 50: 402-410.

Zawirska I (1976). Untersuchungen über zwei biologische Typen von Thrips tabaci Lind. (Thysanoptera, Thripidae) in der VR Polen. Arch Phytopathol Pflanzenschutz 12: 411-422.

Zeigler RS, Morales FJ (1990). Genetic determination of replication of Rice hoja blanca virus within its planthopper vector, Sogatodes oryzicola. Phytopathology 80: 559-566. 